\title{
Metadatos Documentales en el Canal Extremadura Televisión
}

\section{María Jesús Blanco Izquierdo}

\author{
Inés Carmen Poveda López
}

Recibido: 2 de septiembre de 2015

Aceptado: 22 de septiembre de 2015

\section{Resumen}

Se describen y analizan los metadatos facilitados por los gestores de información de Canal Extremadura Televisión en el marco del sistema de gestión documental de la cadena. Los metadatos que se presentan son tanto los asignados para programas informativos como para programas de entretenimiento. Asimismo se muestra un breve estado de la cuestión en materia de metadatos, facilitando la definición de los principales autores en castellano. En este mismo contexto se analiza la estructura del sistema de gestión documental de Canal Extremadura Televisión, así como su historia.

\section{Pallabras clave}

Metadatos, Televisión Pública, Archivos Audiovisuales, Canal Extremadura, Gestión de la Información

\section{Audiovisual Metadata in Canal Extremadura Televisión}

\section{Abstract}

This article describes and analyzes the metadata defined by the information management team of Spanish regional TV broadcaster Canal Extremadura Televisión, as used in their documentation management system. The presented metadata covers both news as well as entertainment broadcasts. The article also offers a brief introduction to the metadata problem space, including the most important Spanish-language authors in this area - as well as an analysis of the documentation management system of Canal Extremadura Televisión, including its history.

\section{Keywords}

Metadata, Public Television, Audiovisual Archives, Canal Extremadura, Information Management

http://dx.doi.org/10.5209/rev CDMU.2015.v26.50633 


\section{OBJETIVOS Y METODOLOGÍA}

Se pretende con este artículo describir de forma exhaustiva la estructura de metadatos establecida para la descripción de la documentación audiovisual en Canal Extremadura Televisión, tanto en documentación de programas como en documentación de informativos, y tanto en formato analógico como en formato digital.

Para ello se ha procedido a analizar y describir los campos y áreas de las bases de datos en que se gestiona dicha documentación audiovisual en Canal Extremadura (On Air y Dalet), así como a revisar bibliografía relacionada con los metadatos en el ámbito de lo audiovisual.

Se aborda en primer lugar una visión teórica general de los metadatos audiovisuales, así como de la historia y características específicas de Canal Extremadura Televisión, para posteriormente dar paso a la descripción detallada de los metadatos documentales en Canal Extremadura.

\section{INTRODUCCIÓN A LOS METADATOS EN TELEVISIÓN}

La etimología de Metadatos nos dice de éstos que son "datos sobre datos", es decir, que se trata de objetos que proporcionan información sobre otros datos.

Tal como afirma De Jong (2003) no existe un consenso en cuanto a la definición de "metadatos", y dependiendo de la orientación de los autores (profesionales técnicos o profesionales de la información) se enfatizan unos aspectos u otros.

En el contexto de lo audiovisual, y profundizando algo más en el concepto, podemos definir Metadatos como descripciones estructuradas de un objeto de información que tienen como finalidad hacer útiles los datos, es decir, describir información y organizar el conocimiento para posteriormente recuperar y utilizar esa información o conocimiento. (Méndez Rodríguez, 2002).

Son, pues, una herramienta para "describir, identificar, definir, organizar y localizar distintos tipos de recursos de información" tanto analógicos como digitales (Orozco García-Mayorca, 2001?) y van a permitir la normalización, tanto para describir la información como para facilitar su intercambio entre distintas plataformas (en el caso de información digital).

Sin embargo, los metadatos son información significativa siempre que no sean una mera información aislada, es decir, la agrupación de varios metadatos es necesaria para transmitir información útil. La información no es conocimiento per se, solo cuando las piezas adecuadas de información se perciben en un correcto entramado de relaciones, nace ese conocimiento. (Cox et al., 2007)

Por tanto, los metadatos hacen que la asociación de varios tipos de datos de diversa índole, ofrezcan una información de mayor calidad y una mejor gestión de dicha información, que estará mejor clasificada y cuya recuperación será más rápida y eficaz.

Orozco García-Mayorca (2001?) establece las funciones básicas de los metadatos: 
Proporcionar la descripción de un objeto o entidad de información junto con otra información necesaria para su manejo y preservación.

Suministrar los puntos de acceso a esa descripción.

Codificar la descripción para facilitar su manejo por medios automatizados.

Los metadatos van más allá de la catalogación, aunque beben de los sistemas tradicionales y están ligados a aquella, en tanto que sus funciones y objetivos son los mismos, es decir, la recuperación de la información que describen a través de la representación de dicha información.

En la última década, tal y como plantean López Yepes, Sánchez Jiménez y Pérez Agüera (2003), varios factores van a favorecer la conciencia por parte de las empresas del sector audiovisual de la necesidad de estructurar la información para facilitar los procesos de producción y distribución. Estos factores son fundamentalmente el uso masivo de internet para la distribución de contenidos, y por otro lado, la digitalización de estos contenidos audiovisuales.

La digitalización se hace presente en todo el proceso del activo audiovisual, desde su producción hasta su difusión, conservación, intercambio y comercialización, ya que posibilita implementar todos estos procesos de forma más sencilla que con la antigua producción en cinta y, particularmente en el ámbito de los archivos audiovisuales, se convierte en la opción más viable para una adecuada conservación de sus fondos.

Las empresas audiovisuales van a producir, pues, gran cantidad de recursos que, para poder ser gestionados deben ser estructurados a través de metadatos (Polo Carrión, Caldera Serrano, Poveda López, 2011).

A este respecto, las televisiones públicas han tendido a establecer sus propias políticas y procedimientos para conservar y gestionar sus producciones en formatos analógicos. Con el aumento de las posibilidades de edición digital, muchas cadenas han reconocido la necesidad de organizar mejor su archivo y estandarizar métodos para gestionar mejor sus productos digitales; sin embargo, con esta proliferación de la producción digital y los flujos de distribución que trabajan para una gran variedad de sistemas, ya no es viable para las televisiones utilizar sistemas tan individualistas y se hace fundamental que adopten estándares comunes para la descripción y el intercambio. (Weisse, Ide, Van Malssen, 2007). Así pues, tal y como afirma Méndez Rodríguez (2002) cualquier sistema de gestión de información debe estar dirigido a las necesidades concretas de la empresa en que va a ser utilizado, pero además, se debe acomodar a los protocolos y normas utilizados en la normativa internacional.

La complejidad que le es propia a la documentación audiovisual, tanto por el tipo de información que puede contener (locución, imagen en movimiento, texto, música,...), como por los procesos de los que forma parte dentro de la empresa audiovisual (producción, edición, difusión y archivo), hace que la información asociada que genera sea mucha y muy diversa, por tanto, la tipología de metadatos para estructurar la documentación audiovisual también será variopinta, desde los metadatos que podrían asemejarse a los puntos de acceso empleados en la catalogación tradicional, hasta metadatos de contenido, metadatos técnicos, de tipo legal, etc. 
Para conseguir, pues, una descripción rica que facilite la recuperación deseada, es importante plasmar toda esta diversidad de información. (Caldera Serrano; Arranz Escacha, 2012).

Los metadatos pueden ir integrados en el propio activo audiovisual al que definen (en el caso de activos digitales), o bien pueden estar asociados a dicho activo (en el caso de activos analógicos y digitales). Asimismo, la generación de metadatos puede realizarse desde distintas áreas dentro de una misma organización, pudiendo ser automática o manual.

Orozco García-Mayorca (2001?) habla de la figura del documentalista audiovisual en la generación de metadatos, y afirma que para realizarla se requieren competencias que abarcan desde conocer e identificar distintos soportes y formatos, conocer el lenguaje audiovisual, identificar las áreas que componen la descripción catalográfica y de contenido hasta el diseño o aplicación de bases de datos que permitan organizar la información para una recuperación rápida y exhaustiva.

Existe poca normativa de estándares de metadatos para documentos audiovisuales, siendo particularmente escasa la centrada en televisión (Polo Carrión, Caldera Serrano, Poveda López, 2011). No vamos a extendernos en la enumeración de estándares, pero cabe mencionar la Lista de Datos Mínimos de la FIAT/IFTA (que no es un estándar de metadatos propiamente dicho, pero que ha servido como referente a estándares posteriores y de base para la descripción en distintas empresas de televisión, como afirma Caldera Serrano [1999]); Dublin Core; TV Anytime; SMPTE; PREMIS; MPEG, etc.

\section{CANAL EXTREMADURA TELEVISIÓN}

La televisión y la radio autonómicas de Extremadura nacen con la aprobación de la Asamblea de Extremadura en noviembre de 2000 de la Ley 4/2000, de 16 de noviembre, por la que se crea la empresa pública "Corporación Extremeña de Medios Audiovisuales" (CEXMA) y sus sociedades filiales.

En esta ley, así como en la posterior Ley 3/2008, de 16 de junio, reguladora de la empresa pública "Corporación Extremeña de Medios Audiovisuales", se fijan como objetivos la creación de una radio y televisión públicas que contribuyan a dar a conocer la historia y cultura de la región, den cabida al conjunto de la sociedad, apuesten por programas educativos y culturales; preserven la diversidad cultural y tradiciones extremeñas; sean objetivas, veraces, imparciales, además de plurales, y protejan a la juventud, promuevan la igualdad y eviten cualquier forma de discriminación, entre otros; y se incide particularmente en su función de servicio público.

Asimismo, se fija en el $60 \%$ el porcentaje de la parrilla que debe realizarse con producción propia, distribuyéndose esta entre producción interna y producción propia delegada a productoras.

En este contexto, Canal Extremadura Televisión, la televisión pública extremeña, nace el 27 de marzo de 2005. Su sede se establece en Mérida, la capital autonómica, y comienza sus emisiones en pruebas el 1 de diciembre de ese mismo año. 
El 7 de junio de 2006 emite su primer informativo, "Extremadura 20:30", y en febrero de 2007 nace su segundo canal, Extremadura TV, actualmente denominado Canal Extremadura SAT, destinado al público residente fuera de la región.

En 2011 se produce la fusión de las dos sociedades filiales de la CEXMA, englobándose radio y televisión en una sola empresa.

\section{ESTRUCTURA DOCUMENTAL EN CANAL EXTREMADURA}

El servicio de documentación de Canal Extremadura Televisión dependía orgánicamente en su origen (noviembre de 2005) de dos departamentos diferentes: el departamento de Programas y el departamento de Producción.

Al primero de ellos se adscribía "Documentación de programas" y al segundo "Documentación de informativos".

Existían, pues, dos centros de tratamiento y gestión documental, que se encontraban separados tanto orgánica, como físicamente, y en procedimientos y herramientas.

Finalmente, desde noviembre de 2011, y tras una reestructuración de la empresa, estos dos centros se unieron en el organigrama, pasando a depender ambos del nuevo departamento de Producción y Programas de Televisión, y compartiendo los documentalistas el mismo espacio físico.

En "Documentación de programas" reciben tratamiento documental en distinto grado de descripción todos los programas editados, copias limpias y brutos de grabación de programas del Canal en soporte de cinta. Además, da tratamiento a toda la producción ajena, sujeta a derechos de emisión (series de ficción, documentales y películas en su mayor parte.)

"Documentación de informativos" por su parte, no analiza estos programas, pero sí atiende las necesidades de imágenes de las productoras que los crean. Se encarga de guardar, analizar y procesar todas las piezas editadas del informativo diario de Canal Extremadura y los brutos que se graban para elaborar las noticias y como recursos de archivo, así como las noticias de agencia; todo ello en formato digital.

Los límites entre ambos servicios son difusos, puesto que aunque la denominación sea "Documentación de Programas" y "Documentación de Informativos", la diferencia real no viene dada tanto por el tipo de imagen que se trata, (programas de entretenimiento y programas informativos) sino por el soporte en el que se halla fijada la imagen (soporte cinta o material digitalizado). Esto se deriva en el uso de dos aplicaciones diferentes para la gestión de dichas imágenes; On air en el caso de Programas y Dalet en el de Informativos.

Por otro lado, los usuarios son potencialmente los mismos para ambos centros, pero con algunas particularidades que definen también esta distinción conceptual. Así, "Documentación de Informativos" atiende casi en su totalidad las peticiones de la redacción para la elaboración del informativo diario y también las demandas de imágenes de archivo para programas de la cadena en general. En el caso de "Documentación 
de Programas", los usuarios son más heterogéneos y las demandas de programas completos son mayoría respecto a las de imágenes concretas que forman parte de los programas.

Paulatinamente, se están integrando ambos aspectos, de modo que todos los documentalistas del departamento realicen las funciones tradicionalmente definidas como "de Programas" y "de Informativos". La integración en una única aplicación, sin embargo, no existe por el momento y se sigue trabajando con dos bases de datos totalmente independientes.

\section{METADATOS DE LAS BASES DE DATOS DE CANAL EXTREMADURA TELEVISIÓN}

\section{Metadatos en el Área de Programas}

La base de datos en la que se gestionan los documentos audiovisuales fijados en soporte cinta, On Air, forma parte de un sistema global de gestión de la emisión televisiva, que relaciona áreas como Programación, Publicidad, Autopromoción, Control de calidad, Gestión de contenidos, Administración, Continuidad y Documentación.

La parte que se utiliza para gestionar todos los programas y soportes en Documentación incluye dos repositorios: Programa/Serie y Largometrajes/Especiales, distinguiendo así entre programas únicos y programas seriados.

A su vez, en el repositorio Programa/Serie puede descenderse de nivel hasta cada uno de los episodios que constituyen el programa.

En On air hay más campos que son visibles para Documentación, pero no lo vamos a indicar en la descripción de los metadatos, en tanto que no tienen ninguna relación con la actividad de este servicio. Se relacionan a continuación los campos que directa o indirectamente implican a Documentación, tanto si es para completarlos como para consultarlos.

En los campos de análisis de contenido, el nivel de descripción varía de un documento a otro, dependiendo de varios factores, tales como: derechos de reutilización de las imágenes, tipo de edición y postproducción del documento audiovisual, valor de reutilización del contenido de los programas, etc. Así pues, no tendrá el mismo potencial de reutilización un concurso que un reportaje de investigación, por ejemplo, y esto se va a reflejar asimismo en la profundidad del análisis.

A continuación, señalamos los metadatos asignados para programas:

1. ID.

Se trata de un código alfanúmerico obligatorio que asigna el sistema automáticamente y que identifica de forma única cada componente del mismo. En On air cada registro tendrá un ID propio.

2. TÍTULO. 
Es el nombre que recibirá cada registro. Este campo alfanumérico es obligatorio y lo genera una persona del departamento de Administración, si bien es Documentación quien posteriormente lo modifica en caso necesario y le otorga su forma definitiva, tal y como aparece en la fuente principal. En términos generales los materiales que ingresan en el sistema ya cuentan con un título desde su creación, por tanto el documentalista, a diferencia de en el caso de informativos, no tiene que "crear" ese título.

\section{TÍTULO ORIGINAL.}

Se trata del título original en otro idioma diferente del español del documento que se registra. Se toma de la fuente original o de fuentes secundarias.

Es un campo alfanumérico no obligatorio y lo completa Documentación.

\section{TÍTULO ALTERNATIVO.}

Se consigna cuando en la fuente original o en fuentes secundarias figuran otros títulos para el documento que se registra diferentes del principal en el mismo idioma.

Es un campo alfanumérico no obligatorio y que completa Documentación.

\section{TIPO DE PRODUCCIÓN.}

Se refiere a si el producto audiovisual es de producción propia, propia delegada, coproducción o producción ajena, dependiendo de ello los derechos que se tengan sobre la obra.

Es un campo obligatorio que consigna Administración de una lista normalizada.

\section{NÚMERO DEL EPISODIO.}

Se trata al número de orden que tiene un episodio dentro de la serie o programa seriado al que pertenece, siendo este pensado desde el origen de la producción.

Es un campo numérico obligatorio y se genera automáticamente en On air cuando se crean todos los episodios de una serie, aunque es posteriormente cuando Documentación registra cada episodio y asocia su contenido al registro correspondiente.

\section{NÚMERO DE ORDEN DE EMISIÓN.}

Se trata del número que se asigna a los episodios de una serie o programa seriado y que establece el orden en que se van a emitir, siendo posible pues, diferir este orden del orden original que recibió el episodio en su producción.

Es un campo numérico y obligatorio y como en el caso anterior se genera automáticamente al crear los episodios, siendo por defecto ambos campos idénticos. En el caso de que se quiera usar este campo para establecer un orden distinto al original, la modificación la hace Documentación. 


\section{ESTADO DE LA PRODUCCIÓN.}

Campo obligatorio que completa Documentación con la información del parte de Control de Calidad que acompaña a la cinta y en el que se indica si un programa es apto o no para su emisión atendiendo a sus características técnicas. Los distintos estados del material vienen predefinidos en una lista normalizada. Igualmente, se indica en este campo si un material causa baja en el sistema. Este proceso pasa únicamente por Documentación.

\section{DURACIÓN NETA.}

Este es un campo obligatorio de formato hora (horas:minutos:segundos:frames) y en él se indica la duración exacta del programa. Lo calcula automáticamente el programa una vez completados manualmente los campos de TC IN y TC OUT.

\section{DURACIÓN EN BRUTO.}

Campo obligatorio de formato hora en el que se consigna manualmente por parte de Administración la duración aproximada del documento audiovisual registrado, con el fin de poder incluirlo en la parrilla de programación incluso antes de haber sido visionado.

11. TC IN.

Indica el código de tiempo en que comienza el programa dentro de la cinta que lo contiene. Se trata de un campo obligatorio que utiliza un formato hora (horas:minutos:segundos:frames) y que es completado por el servicio de Control de calidad.

12. TC OUT.

Indica el código de tiempo en que finaliza el programa dentro de la cinta que lo contiene. Es un campo obligatorio de formato hora y lo completa el servicio de Control de calidad.

\section{DURACIÓN DEL SOPORTE.}

Campo obligatorio en formato hora que expresa la longitud en horas y minutos del soporte de vídeo, independientemente de la parte utilizada en la grabación. Lo completa Documentación.

14. GÉNERO.

Campo alfanumérico de carácter obligatorio que completa el documentalista y en el que se indica la tipología de programa de televisión a la que pertenece según su temática. Existe una lista normalizada de la que se selecciona el género correspondiente a cada programa.

\section{CALIFICACIÓN MORAL DEL MINISTERIO DE CULTURA.}

Indica la calificación que otorga el Ministerio de Cultura (MCU) a todas las películas previamente a su comercialización, y a través de la cual se distingue por grupos de edad el público al que va dirigida una película. 
Es un campo alfanumérico y obligatorio que completa Documentación de una lista normalizada y previa consulta de la base de datos del MCU.

\section{CALIFICACIÓN MORAL DE CANAL EXTREMADURA.}

Puesto que la calificación del Ministerio de Cultura solo se realiza sobre películas, quedando fuera el resto de producciones audiovisuales, Canal Extremadura otorga una calificación propia, de modo que se califiquen así todas las obras susceptibles de emisión o reutilización y que formen parte de su archivo audiovisual.

Es un campo alfanumérico y obligatorio que completa Documentación de una lista normalizada, aunque la calificación la hace el servicio de Control de calidad.

\section{TIPO DE PROGRAMA.}

En este campo se recoge el formato televisivo del programa, refiriéndonos a formato televisivo como las características formales que definen un programa, siendo las características de contenido las que aluden al género.

Es un campo obligatorio tomado de una lista normalizada y que asigna Documentación.

\section{CLASIFICACIÓN DE PROGRAMA.}

Canal Extremadura utiliza este campo para clasificar la producción ajena (especialmente películas y tv movies) dentro de unos criterios establecidos para facilitar su programación en franjas dirigidas a un público determinado. Dicha clasificación alude a si la producción es clásica o actual, o corresponde a cine europeo, español, estadounidense o del resto del mundo.

Es un campo obligatorio, que completa Documentación de una lista predefinida.

19. FILLER.

Este campo se utiliza para clasificar los elementos pequeños, como clips, que se utilizan para ajustar la parrilla de programación, en distintas categorías, de modo que estos elementos quedan agrupados según su temática. Se trata de un campo de texto alfanumérico, no obligatorio, y lo completa Documentación.

20. IDIOMA ORIGINAL.

En este campo se consigna la lengua en que se ha realizado el documento audiovisual en su versión original.

Se trata de un campo obligatorio que completa Documentación de una lista predeterminada.

\section{AÑO DE PRODUCCIÓN.}

Campo obligatorio con formato de año (cuatro dígitos) en el que se incluye el año de la obra que se registra.

22. FORMATO. 
Campo obligatorio completado por Documentación que alude al formato del soporte de grabación. Se selecciona de una lista de formatos predefinida. En el caso de que una misma serie se haya grabado en varios formatos, se indicará en el nivel Programa/Serie el formato más empleado y en el nivel Episodio se recogerá cada formato en concreto.

23. COLOR.

Campo obligatorio completado por Documentación en el que se indican las características de color del documento, siendo las opciones posibles: "color", "blanco y negro" y "material coloreado".

24. CARACTERÍSTICAS DE SONIDO.

Campo obligatorio en el que el servicio de Control de Calidad indica características del sonido tales como si es dual, el idioma de los diferentes canales de audio, si se trata de audios mezclados o separados, y otras características como la existencia de subtitulación o de lengua de signos. Esta información se selecciona de distintas listas normalizadas. Documentación puede consultar estas características, pero no completa esta información.

\section{RELACIÓN DE ASPECTO.}

Se consigna en este campo la proporción de la imagen en relación a su anchura y su altura. Los más habituales en el archivo de Canal Extremadura son 4:3 y 16:9.

Es un campo obligatorio de formato alfanumérico. Lo completa el servicio de Control de calidad y Documentación puede consultarlo.

26. FECHAS DE EMISIÓN.

Esta información consta de varios campos que completa automáticamente el sistema una vez que un programa se ha emitido o está programada su emisión, tomando los datos del servidor de emisión en el primer caso y de la pauta de programación en el segundo. Se toma la fecha de programación (formato fecha, [día/mes/año]), la fecha de emisión (formato fecha), el canal en el que se ha emitido el programa (texto alfanumérico), y la hora de emisión (formato hora).

\section{LUGAR DE PRODUCCIÓN.}

Campo obligatorio que recoge el país o países correspondientes a la nacionalidad o nacionalidades de la obra que se registra. Lo completa Documentación de una lista normalizada previamente establecida.

28. NOTAS.

Campo alfanumérico de texto libre usado generalmente por el documentalista, aunque está accesible para más tipos de usuario. Es un campo opcional y se utilizará siempre que se considere que es necesario ampliar la información de cualquier aspecto del registro.

29. SINOPSIS. 
Campo en el que se incluye el resumen del contenido de un programa, tanto si es de producción ajena como propia, de ficción o no ficción.

Se trata de un campo alfanumérico de texto libre que completa Documentación, sirviéndose tanto de fuentes externas como elaborándolo directamente. Es de carácter obligatorio.

\section{DELEGADO DE CANAL EXTREMADURA.}

Campo de texto libre en el que se consigna la persona responsable en Canal Extremadura de la supervisión de cada programa de producción propia delegada, para comprobar que este se ajusta a los requerimientos que la cadena hace a la productora a la que se encarga el programa. Lo completa Documentación.

\section{DIRECTORES E INTÉRPRETES.}

Campo opcional de texto libre en el que se indica el principal responsable intelectual del producto audiovisual que se registra, sea este de ficción o no, y las personas que aparecen en el mismo actuando, en este caso únicamente en los programas de ficción. Lo completa Documentación.

32. EPG.

Siglas de Electronic Program Guide, este campo sirve para incluir la información que queremos que se vea posteriormente en el terminal de televisión digital, incluyendo generalmente información tal como la sinopsis, el año de producción, el director del programa, etc.

Es un campo alfanumérico de texto libre y de carácter opcional (aunque se recomienda su uso), y lo completa Documentación en el caso de producción ajena y el departamento de Gestión de contenidos y programas en el caso de la producción propia y propia delegada.

33. LISTADO.

Este campo opcional de texto libre se pensó para poder incluir los distintos descriptores (onomásticos, temáticos, geográficos, etc. tanto visualizados como referenciados) dado que no existen campos normalizados construidos expresamente para este cometido en On air, que no es una base de datos documental. Lo completa el documentalista.

34. MINUTADO.

En este campo se incluye la descripción secuencial del contenido del documento audiovisual, siempre en los casos de poder reutilizar dichas imágenes, generalmente en documentos de producción propia y propia delegada.

Es un campo de tipo alfanumérico de texto libre y de carácter opcional que realiza Documentación.

\section{PRESENTADOR.}

Se recoge en este campo el nombre de la persona que conduce un determinado espacio televisivo. Es de carácter opcional, alfanumérico y de texto libre, y lo completa Documentación. 


\section{PRODUCTOR.}

Se consignará en este campo el nombre de la persona que haya realizado las labores de producción o producción ejecutiva de un programa listo para su emisión.

Es un campo opcional alfanumérico y de texto libre que completa Documentación.

\section{REALIZADOR.}

Se indicará en este campo el nombre de la persona que haya llevado a cabo las labores de realización de un programa listo para su emisión.

Es un campo opcional de texto libre. Lo completa Documentación.

38. CREADO POR.

Nombre de la persona que da de alta el registro en el sistema y que pertenece al departamento de Administración. Este campo se completa automáticamente, siendo el usuario identificado por su código de acceso al sistema. Es visible para todos los usuarios y no se puede modificar.

\section{MODIFICADO POR.}

Nombre de la persona que realiza algún cambio en el registro una vez que ya ha sido dado de alta. Queda consignado cualquier usuario del sistema y por tanto, también los documentalistas. Al igual que el campo anterior, la información se toma de la sesión del usuario.

\section{FECHA DE CREACIÓN.}

Se trata de un campo obligatorio que genera On Air automáticamente cuando se crea un registro y tiene formato de fecha (día/mes/año).

\section{FECHA DE MODIFICACIÓN.}

Al igual que en el caso anterior este campo de formato fecha se genera automáticamente cuando cualquier usuario del sistema realiza un cambio sobre un registro.

\section{DERECHOS.}

Administración consigna el periodo durante el cual se puede emitir un producto audiovisual (formato fecha) y el número de pases de dicho material (campo numérico). Documentación solo puede acceder a esta información para su consulta. Los derechos de reutilización de imágenes no se expresan en la base de datos.

\section{VERSIÓN DEL MEDIA.}

Este campo recoge la tipología del documento audiovisual, ya se trate de máster de emisión, copia, clean feed (máster sin rótulos y con audios separados), brutos, etc. 
Es un campo obligatorio de tipo textual y que completa Documentación de una lista preestablecida.

\section{NÚMERO DE CINTA.}

Campo alfanúmerico obligatorio que consigna Documentación. Identifica a cada uno de los soportes que constituyen el archivo de cintas de Canal Extremadura.

Se trata también de la clave de localización de la cinta en el depósito, dado que su instalación se hace por número correlativo.

45. LOCALIZACIÓN.

Se consigna en este campo el depósito en que se encuentra el material audiovisual fijado en soporte físico, o bien el usuario que ha recibido este material en préstamo durante un periodo de tiempo determinado.

Se trata de un campo alfanumérico, obligatorio, cuyo contenido se toma de una lista preestablecida. Lo completa Documentación.

\section{Metadatos en el Área de Informativos}

Dalet es un software de gestión de contenidos audiovisuales digitales estructurado mediante un sistema de trabajo en grupo que incluye a Documentación, Redacción, Edición, Realización, etc. En el área de Archivo se analizan y describen los activos digitales que van a formar parte del archivo definitivo de la cadena. A través de este sistema se da cobertura al servicio de Informativos fundamentalmente.

Describiremos a continuación los metadatos que directa o indirectamente están relacionados con el área de Documentación y el trabajo de los documentalistas.

\section{GENERAL}

\section{PROCEDENCIA.}

Es un campo que indica el origen de las imágenes que van a formar parte del archivo, bien sea una delegación, una agencia de noticias, una productora, ENG, señales institucionales, etc.

Es un campo alfanumérico, de texto libre y de carácter obligatorio que completa Documentación.

\section{TÍTULO DE DOCUMENTACIÓN.}

Se consigna en este campo una frase significativa que describa de forma sintética y precisa el contenido del documento. Es un campo alfanumérico, de texto libre, de carácter obligatorio y que completa el documentalista.

3. TÍTULO DE LA PIEZA. 
Este campo recoge el nombre que recibe el activo digital en el momento en que se crea en el sistema de gestión, es decir, el que le da el redactor que elabora la pieza, el editor del informativo, o, en el caso de brutos sin editar, el que recibe de la agencia de noticias, del redactor que descarga en ingesta lo que ha grabado, o de cualquier otro que descargue un activo en el sistema.

En este caso Documentación conserva el título original en el caso de piezas editadas, y modifica el título de los brutos sin editar.

Es un campo obligatorio, de texto libre y carácter alfanumérico.

\section{OBSERVACIONES DOCUMENTALISTA.}

Este campo se utilizará siempre que se considere que es necesario ampliar la información de cualquier aspecto del registro.

Campo alfanumérico, opcional, de texto libre que completa el documentalista.

\section{CONTENIDO DE TEXTO.}

Campo en el que se incluye el resumen del documento.

Se trata de un campo alfanumérico de texto libre y carácter obligatorio, que completa Documentación, sirviéndose tanto de fuentes como escaletas, scripts de agencias, etc., como elaborándolo directamente.

6. DURACIÓN DEL TÍTULO.

Campo obligatorio de formato hora (horas:minutos:segundos) y en él se indica la duración exacta del documento. Lo asigna automáticamente el propio sistema y no se puede modificar.

7. SECCIÓN.

Se indica en este campo el área temática a la que corresponde el activo que recibe tratamiento en la base de datos. Se corresponden estas áreas con las clásicas de los medios de comunicación: Regional, Nacional, Deportes, El tiempo, etc.

La selecciona Documentación de una lista normalizada.

8. SERIE.

Este campo recoge el programa en el que se ha emitido la noticia editada o, en su caso, si se trata de un bruto.

Lo selecciona el documentalista de una lista normalizada.

\section{FECHA DE GRABACIÓN.}

Este campo con formato fecha (día/mes/año), muestra la fecha de grabación en el caso de brutos sin editar. Lo completa manualmente Documentación con la información que ya acompaña al activo audiovisual desde el momento de su ingesta. 


\section{FECHA Y HORA DE EMISIÓN.}

Campo de formato fecha y hora que indica el momento en que se emitió el activo audiovisual en el caso de noticias editadas.

Lo completa el documentalista.

\section{FECHA DE ENTRADA EN DOCUMENTACIÓN.}

Se corresponde con la fecha en que el activo audiovisual entra en el módulo de archivo del sistema de gestión digital de noticias, donde posteriormente recibir tratamiento documental.

Campo obligatorio de formato fecha que asigna el sistema automáticamente y no se puede modificar.

12. MINUTADO.

Se indica en este campo la descripción secuencial del contenido del documento audiovisual.

Es un campo de tipo alfanumérico de texto libre y obligatorio que completa Documentación.

\section{Descriptores.}

13. IDENTIFICADOR.

Se consigna en este campo un descriptor que va a permitir agrupar una serie de noticias relacionadas temáticamente con un acontecimiento de gran alcance.

Es un campo opcional que completa el documentalista de una lista normalizada de identificadores.

\section{TEMAS.}

En este campo se consignarán todos los descriptores necesarios para representar el contenido conceptual del documento que se esté describiendo.

Es un campo opcional, que completa el documentalista de un lenguaje controlado.

\section{PLANO TEMAS.}

En este campo se consignarán los descriptores para representar el contenido visual del documento tratado.

Es un campo opcional, que completa el documentalista de un lenguaje controlado.

\section{LUGAR.}

En este campo se indica a través de descriptores el lugar o lugares donde se desarrollan los acontecimientos o de los que trata el documento.

Es un campo opcional, que completa el documentalista de un lenguaje controlado. 


\section{PLANO LUGAR.}

En este campo se consignan los descriptores que aluden al lugar o lugares que se pueden visualizar en el documento.

Es un campo opcional, que completa el documentalista de un lenguaje controlado.

\section{PERSONA O ENTIDAD.}

Campo que se completa con descriptores que representan a las personas, físicas o no, referenciadas en un documento.

Es un campo opcional, que completa el documentalista de un lenguaje controlado.

\section{PLANO PERSONA O ENTIDAD.}

Campo que se completa con las personas, físicas o no, visionadas en el documento.

Es un campo opcional, que completa el documentalista de un lenguaje controlado.

\section{Cuadro Técnico.}

20. REDACTOR.

En este campo se consigna el nombre del periodista autor de la pieza o reportaje que se emite en el programa informativo.

Es un campo opcional, alfanumérico, de texto libre y que completa Documentación.

21. CÁMARA.

Este campo recoge el nombre del operador de cámara que graba las imágenes que posteriormente se van a utilizar para realizar la noticia.

Se trata de un campo opcional, alfanumérico y de texto libre que completa Documentación.

22. INVITADOS.

Se indicarían en este campo el nombre de las personas que intervienen en el programa informativo de forma no habitual y generalmente aportando su conocimiento en un campo específico.

Es un campo opcional, alfanumérico y de texto libre que completa el documentalista.

23. EDITOR.

En este campo se indica el nombre del máximo responsable intelectual del informativo, es decir, la persona que decide qué información se va a emitir y su lugar y tratamiento en el informativo. 
Es un campo opcional, alfanumérico y de texto libre que completa el documentalista.

24. PRODUCTOR.

Se consignará en este campo el nombre de la persona que haya realizado las labores de producción del programa informativo.

Es un campo opcional, alfanumérico y de texto libre que completa Documentación.

\section{DOCUMENTALISTA.}

Se indica en este campo el nombre de la persona que realiza el análisis documental de las imágenes.

Es un campo opcional, alfanumérico y de texto libre que completa Documentación.

26. REALIZADOR.

Se indica en este campo el nombre de la persona responsable de las labores de realización del informativo

Es un campo opcional de texto libre. Lo completa Documentación.

\section{CONTROL.}

Campo que muestra un historial de cada cambio de estado que ha experimentado el archivo audiovisual, así como quién lo ha realizado y cuándo se ha llevado a cabo.

Lo completa el sistema automáticamente.

\section{OTROS METADATOS}

(no incluidos en la descripción documental, pero accesibles y útiles para los documentalistas)

28. FORMATOS.

Corresponde al campo RELACIÓN DE ASPECTO de la base de datos de Programas.

Es un campo obligatorio de formato alfanumérico. A diferencia de en On Air, este campo lo completa el sistema automáticamente al estar las imágenes digitales integradas en el mismo. Documentación puede consultarlo y, en el caso de imágenes en 4:3 modificar este ratio para pasarlo a 16:9.

\section{FECHA DE CREACIÓN.}

Es un campo de formato fecha que indica cuándo el activo audiovisual entra a formar parte del sistema, bien a través de la ingesta de brutos sin editar, o bien a través de la creación de nuevos vídeos editados.

Lo registra el sistema automáticamente.

30. ID. 
Código numérico obligatorio que asigna el sistema automáticamente y que identifica de forma única a cada activo digital del mismo.

31. STATUS.

Indican si los medias del activo audiovisual se encuentran en línea o no y, en ese caso, deben ser recuperados.

Es un campo que recoge el sistema automáticamente.

\section{KEYWORDS.}

Los keywords son palabras clave en lenguaje libre que el redactor va a completar en el momento en que las imágenes que ha grabado son ingestadas en el sistema y que desde ese momento quedan asociadas al activo audiovisual.

Con estos keywords se facilita la labor posterior de Documentación, puesto que a través de ellos se indican los nombres de las personas, lugares o cualquier otro tipo de información relacionada con el contenido de la imagen o su utilización futura.

Se completan en texto libre y son opcionales.

\section{3. ÚLTIMA MODIFICACIÓN.}

Refleja el nombre de la persona que realiza un cambio en el activo digital, así como la fecha y la hora en que se realiza dicho cambio.

Lo registra el sistema automáticamente.

\section{CONCLUSIONES}

Frente a la tendencia de la inclusión de cada vez más cantidad de metadatos desde el ingreso del activo audiovisual en el sistema (Caldera Serrano, 2015; Meana Alonso et al., 2010) antes de llegar al servicio de Documentación para su tratamiento en profundidad, en Canal Extremadura, este modelo está menos implantado.

Si bien, la generación de los metadatos de los que hemos tratado está relacionada con el departamento de Documentación, tanto directamente como de forma tangencial, también intervienen otros departamentos tan diversos como el de Redacción, Administración, Control de Calidad, Gestión de contenidos y programas, etc.

La cantidad y tipología diversa de metadatos asociados a un activo audiovisual hace que su descripción permita la recuperación por muchas vías y de forma más eficaz.

La digitalización de la producción audiovisual no siempre se ha traducido en una adaptación a dicha tecnología, siendo heredados muchos aspectos propios del análisis de material digital que seguramente pudieran ser digitalizados o al menos adaptados a esta nueva realidad. No obstante, en Canal Extremadura se han realizado grandes esfuerzos por llevar a cabo dicha adaptación, aunque podamos encontrar un número significado de 
información que estaba presente en el material analógico y que sigue siendo absolutamente necesario para la descripción de material digital, garantizando así una mejora en la recuperación documental.

Los metadatos asociados tanto por el departamento de Documentación como por otros agentes dentro de la cadena son una pieza fundamental del engranaje del sistema de la cadena, ya que solo de esta manera se podrán recuperar de forma correcta (evitando los problemas de silencio y ruido documental) la gran cantidad de recursos audiovisuales presente en estas colecciones que cuentan con un incremento prácticamente exponencial de sus contenidos.

\section{REFERENCIAS BIBLIOGRÁFICAS}

Cox, Mike; Tadic, Linda; Mulder, Ellen. Descriptive Metadata for Television: And End-to-end Introduction. New York: Focal Press, 2006.

Jong, Annemieke de (2003). Los metadatos en el entorno de la producción audiovisual: una introducción. México D.F.: Netherlands Audiovisual Archives, 2003.

Caldera Serrano, Jorge (1999). Análisis de las recomendaciones de la FIAT/IFTA sobre los datos mínimos a señalar en las bases de datos de los archivos de televisión. Cuadernos de documentación multimedia, 1999, no 8.

http://pendientedemigracion.ucm.es/info/multidoc/multidoc/revista/num8/caldera.html. (Consultado: 2015-7-2)

Caldera Serrano, Jorge (2015). Externalización de la gestión documental audiovisual en las televisiones por medio de productoras audiovisuales y agencias de noticias. TransInformaçao, 27 (2), pp. 145-156

Caldera Serrano, Jorge; Arranz Escacha, Pilar (2012). Documentación audiovisual en televisión. Barcelona: Editorial UOC.

Extremadura. Ley 4/2000, de 16 de noviembre, por la que se crea la empresa pública Corporación Extremeña de Medios Audiovisuales. Diario Oficial de Extremadura, núm 147, 19 de diciembre de 2000, pp. 12516-12522.

Extremadura. Ley 3/2008, de 16 de junio, reguladora de la Empresa Pública “Corporación Extremeña de Medios Audiovisuales". Diario Oficial de Extremadura, núm 116, 17 de junio de 2008, pp. 16274-16291.

López Yepes, Alfonso; Sánchez Jiménez, Rodrigo; Pérez Agüera, José Ramón (2003).

Tratamiento de la documentación audiovisual en el entorno digital: iniciativas de metadatos y lenguajes de descripción multimedia. El profesional de la información, 2003, vol. 12, no 6, págs. 443-451.

Meana Alonso, Sonsoles; Muñoz de la Peña, Paz; Sáez Carreras, Susana (2010). El gestor del 
archivo, nuevo perfil profesional en la redacción única de TVE. Jornades catalanes d'informació i documentació. 2010. http://www.cobdc.net/12JCD/wpcontent/materials/comunicacions/MEANA gestor archivo nuevo perfil tve.pdf (Consultado: 2015-7-7).

Méndez Rodríguez, Eva María (2003). Metadatos y recuperación de información: estándares, problemas y aplicabilidad en bibliotecas digitales. Gijón: Trea, 2002 (Biblioteconomía y Administración Cultural).

Orozco García-Mayorca, Alejandra (2001?). La construcción de metadatos en el proceso de organización, análisis documental y recuperación de la información en los archivos de imágenes en movimiento. 2001?.

http://www.patrimoniofilmico.org.co/anterior/docs/metadatos.pdf (Consultado: 2015-7-2).

Polo Carrión, Juan Antonio; Caldera Serrano, Jorge; Poveda López, Inés Carmen (2011). Metadatos y audiovisual: iniciativas, esquemas y estándares. Documentación de las Ciencias de la Información, 2011, vol. 34, págs. 45-64.

Weisse, Leah; Ide, Mary; Van Malssen, Kara (2007). Recommended Metadata for Describing Born-Digital Master Programs for Preservation and Deposit with the Library of Congress and Other Digital Repositories. 2007.

http://www.thirteen.org/ptvdigitalarchive/files/2009/10/metadata-guidelines.pdf (Consultado: 2015-7-2) 